\title{
Accuracy of a Pedometer and an Accelerometer in Women with Obesity
}

\author{
Malin Wiklund", Åsa Cider and Monika Fagevik Olsén
}

\begin{abstract}
Department of Physiotherapy and Occupational therapy, Sahlgrenska University Hospital, and Institute of Neuroscience and Physiology/Physiotherapy, Sahlgrenska Academy, University of Gothenburg, Gothenburg, Sweden
\end{abstract}

\begin{abstract}
Aim: The main purpose of this study was to examine the accuracy of a specific pedometer (Silva model Pedometer Plus 56013-3) and accelerometer (Silva model Ex3 plus 56026) in women suffering from obesity. The second aim was to study the impact of BMI, waist and hip circumference and waist-hip ratio on different pedometer and accelerometer positions on the body.

Methods: Forty women with a BMI $>30 \mathrm{~kg} / \mathrm{m}^{2}$ wore two pedometers and two accelerometers during a standardized 6 minute walk test. Accelerometer 1 (A1) was placed around the neck. Accelerometer 2 (A2) was attached to the waistband of the woman's trousers in line with left hip, Pedometer 1 (P1) in line with right hip and pedometer 2 (P2) behind back in line with the spine. During the test an assistant manually counted number of steps, using a hand counter as reference for step accuracy.

Results: Steps registered with the pedometer were significantly different from actual steps counted. The intra class correlations for the actual steps counted compared with the steps registered were $\mathrm{P} 1=0.13, \mathrm{P} 2=0.20, \mathrm{~A} 1=0.99$ and $\mathrm{A} 2=$ 0.41. All correlations between the tested pedometer and accelerometer at the different locations and BMI, waist circumference, hip circumference and hip-to waist ratio were little (if any) or low.
\end{abstract}

Conclusions: The accelerometer is more accurate than the pedometer in measuring steps in women suffering from obesity. The location, which gave the most accurate results, was found to be around the neck.

Keywords: Accelerometer, accuracy, motor activity, obesity, pedometer, walking.

\section{INTRODUCTION}

The increasing prevalence of obesity is a major health threat in both low- and high income countries [1]. Increased levels of physical activity can be used in conjunction with diet to fight obesity and serve as a tool in weight maintenance, which has in addition a large impact on general health [2]. Pedometers or accelerometers could be used in clinical practice to objectively measure the level of physical activity. Furthermore they can be used to increase motivation to enhance the level of physical activity $[3,4]$. The scientific knowledge is divergent concerning the accuracy of the different brands of pedometers used by obese individuals [58]. In the study by Crouter et al. [6], the tilt of their tested pedometer (Yamax SW200) was the most important factor influencing the accuracy compared to the patients' waist circumference and BMI. However none of these three factors influenced the accuracy of the tested accelerometer (New Lifestyles NL-200).

Most manufacturers recommend positioning the pedometer at the hip. However, in obese individuals this may not be an optimal position as it can result in pedometer tilt. Horvath et al. [9] showed that there was a large difference in

*Address correspondence to this author at the Department of Physiotherapy, Sahlgrenska University Hospital 41345 Gothenburg, Sweden; Tel: +46313421195; Fax: +46313424341;

E-mail: malin.wiklund@vgregion.se the amount of steps measured depending on if the pedometer (Yamax SW200) was carried on the left or right side. The authors comment that their findings could not be generalized to other pedometers brands. Other authors have also pointed out that it is important that researchers and practitioners regularly assess and report accuracy of the instrument used [10].

Performance of pedometers and accelerometers is most commonly evaluated against observed steps taken using the established treadmill protocol designed by Basset et al. [11]. On the other hand researchers and practitioners are also interested in how these instruments work in clinical settings and during free-living conditions [10]. de Souza et al. [12] concluded that the 6-minute walk test (6 MWT) is a simple, safe, powerful and objective test that provides useful information about the functional status of patients with obesity undergoing bariatric surgery. Furthermore, the test may be more suitable than the conventional treadmill test for this category of patients. Patients with severe obesity are more likely to be able to perform a 6 MWT, than a standard maximal cycle ergometer or treadmill exercise test [12]. There is however a lack of information about how accurate pedometers and accelerometers are in obese women, in clinical settings such as during a 6 MWT.

The main purpose of this study was to examine the accuracy of a specific pedometer (Silva model Pedometer Plus 56013-3, Silva Sweden AB, Sollentuna, Sweden) and accelerometer (Silva model Ex3 plus 56026, Silva Sweden AB, Sollentuna, Sweden) in women suffering from obesity. 
Table 1. Descriptive Characteristics of Participants $(n=40)$

\begin{tabular}{|l|c|c|}
\hline & Mean $($ SD) & Median $($ Min-Max) \\
\hline \hline Age $($ year) & $42(9)$ & $41(26-63)$ \\
\hline Weight $(\mathrm{kg})$ & $116.0(17.6)$ & $114.0(91.0-174.0)$ \\
\hline Height $(\mathrm{cm})$ & $166.5(0.5)$ & $166.7(156.0-175.6)$ \\
\hline Body Mass Index $\left(\mathrm{kg} / \mathrm{m}^{2}\right)$ & $41.9(6.1)$ & $40.4(34.0-63.1)$ \\
\hline Waist circumference $(\mathrm{cm})$ & $120.5(9.8)$ & $120.5(99.0-143.0)$ \\
\hline Hip circumference $(\mathrm{cm})$ & $134.0(13.2)$ & $132.0(116.0-169.0)$ \\
\hline Waist-to-hip ratio & $0.89(0.08)$ & $0.90(0.74-1.11)$ \\
\hline
\end{tabular}

SD; standard deviation, Min; minimum, Max; maximum.

The second aim was to study the impact of BMI, waist and hip circumference and waist-hip ratio on different pedometer and accelerometer positions of the body.

\section{METHOD}

A convenient sample of forty women with obesity (BMI $\geq 30 \mathrm{~kg} / \mathrm{m}^{2}$ ) awaiting gastric bypass surgery at Sahlgrenska University Hospital in Gothenburg, Sweden participated in the study. After written and verbal information a written informed consent was obtained from all participants. The Regional Ethical Review Board of Gothenburg, Sweden approved the study.

The participants' height and weight were measured in light clothing and without shoes using a wall-mounted stadiometer (Seca, Hamburg, Germany) and a calibrated physicians scale (TANITA, Tokyo, Japan). Body mass index was calculated as the weight in kilograms divided by the square of the height in meters $\left(\mathrm{kg} / \mathrm{m}^{2}\right)$. Circumference measures of the waist and hip were performed according to WHO [13]. One examiner performed all measurements. Table 1 provides descriptive data of the study population.

Inclusion criteria: patients awaiting gastric bypass surgery with estimated procedure within the next three months, and able to understand spoken and written Swedish. Exclusion criteria: neurologic, rheumatologic or orthopaedic injury or illness that would hinder the assessments required in the study.

Two pedometers and two accelerometers were tested during a standardized 6 MWT, using a $30 \mathrm{~m}$ pre-measured course (in a corridor at Sahlgrenska University Hospital). The 6 MWT was performed as described by American Thoracic Society [14].

The pedometers (Silva model Pedometer Plus 56013-3, Silva Sweden AB, Sollentuna, Sweden), Fig. (1), were attached to the waistband of the participant's clothing. One pedometer was placed at the midline of the right hip and one in line with the spine at the lower part of the back. The pedometers comprised a spring-suspended pendulum mechanism to detect vertical movement, which registered every time the pendulum moved up or down. According to the manufacturer the pendulum was calibrated for optimal function and included software to filter out unwanted data, the pedometer therefore began to record once six consecutive steps had been taken. According to the instructions, the pedometer should be placed vertically i.e. not tilting, onto

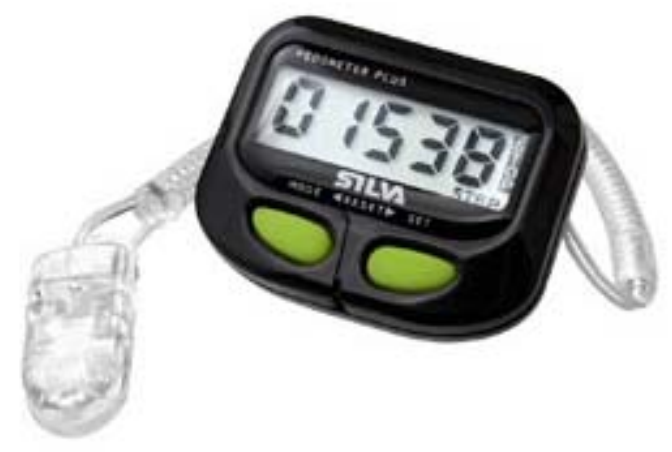

Fig. (1). Silva model Pedometer Plus 56013-3, Silva Sweden AB, Sollentuna, Sweden.

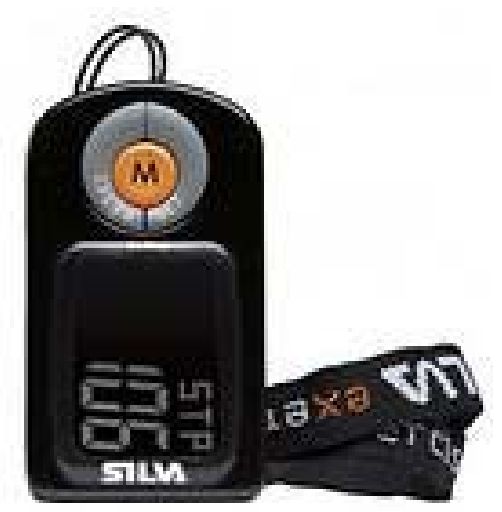

Fig. (2). Silva model Ex3 plus 56026, Silva Sweden AB, Sollentuna, Sweden.

the waistband of the trousers/skirt or on a belt close to the hip. Before the participant began the test, the test leader checked that the pedometers were positioned correctly, that the pedometer sat straight with no tilt.

The accelerometers (Silva model Ex3 plus 56026, Silva Sweden AB, Sollentuna, Sweden), Fig. (2), were placed around the neck as well as at the left hip attached to the waistband of the participants clothing. It contained a 3D sensor to detect movement by using 3 axes: $\mathrm{X}, \mathrm{Y}$ and $\mathrm{Z}$. Depending on how the individual moved, the accelerometer assessed movements using the 3 axes at the same time. It also contained software to interpret the movement and force. This software filters unwanted data and therefore it took 10 seconds before the accelerometer updated the steps taken. According to the instructions from the manufacturer the accelerometer is able to count steps independent of how it is worn as long, it is still and does not swing around during walk, and may for example be hung around the neck.

During the test, one of the authors (MFO), counted steps manually using a hand counter $(\mathrm{CH}-10$, Voltcraft, Hirschau, Germany) to give a reference for step accuracy. To test reliability of the manual registration, another assistant counted the steps also using a hand counter on the same occasion. The registrations of both tests showed $100 \%$ agreement.

To test the outcome measures for reproducibility all participants were asked to repeat the 6 MWT test after one hour, which included at least 20 minutes seated rest. 
Table 2. Distance Walked, Actual Steps Counted, Registered Numbers of Steps and p-Value-Comparison to Actual Counted Steps at the Different Locations $(n=80)$

\begin{tabular}{|c|c|c|c|}
\hline & Mean (SD) & Median (Min-Max) & p-Value \\
\hline Distance walked (m) & $519(84)$ & $519(240-704)$ & - \\
\hline Actual steps counted (number of steps) & $740(82)$ & $744(468-933)$ & - \\
\hline Pedometer, right hip (number of steps) & $602(224)$ & $681(0-864)$ & $<0.001$ \\
\hline Pedometer, back in line with spine (number of steps) & $682(151)$ & $711(0-879)$ & $<0.001$ \\
\hline Accelerometer, around the neck (number of steps) & $737(78)$ & $749(441-926)$ & 0.102 \\
\hline Accelerometer, left hip (number of steps) & $712(127)$ & $737(0-917)$ & 0.015 \\
\hline
\end{tabular}

SD; standard deviation, Min; minimum, Max; maximum

Table 3. Mean (SD) and Median (Min-Max) Error Scores (Steps Detected - Actual Counted Steps) at the Different Positions of the Body During two 6 MWT $(n=40)$

\begin{tabular}{|c|c|c|c|c|}
\hline & \multicolumn{2}{|c|}{$1^{\text {st }} 6 \mathrm{MWT}$} & \multicolumn{2}{|c|}{$2^{\text {nd }} 6 \mathrm{MWT}$} \\
\hline & Mean (SD) & $\begin{array}{c}\text { Median } \\
\text { (Min-Max) }\end{array}$ & Mean (SD) & $\begin{array}{c}\text { Median } \\
\text { (Min-Max) }\end{array}$ \\
\hline Pedometer, right hip (number of steps) & $-137(231)$ & $-25(-909-9)$ & $-140(217)$ & $-59(-893-1)$ \\
\hline Pedometer, back in line with spine (number of steps) & $-44(149)$ & $-5(-903-83)$ & $-72(159)$ & $-15(-834-114)$ \\
\hline Accelerometer, around the neck (number of steps) & $-1(9)$ & $0(-39-14)$ & $-5(17)$ & $-2(-86-31)$ \\
\hline Accelerometer, left hip (number of steps) & $-39(153)$ & $-6(-909-105)$ & $-17(59)$ & $-6(-172-111)$ \\
\hline
\end{tabular}

SD; standard deviation, Min; minimum, Max; maximum

All pedometers and accelerometers used in this study were checked to be in working condition using a shake test as described by Vincent et al. [15]. If the error exceeded \pm $1 \%$ in the shake test, that pedometer or accelerometer was not used in this study. As recommended by Sidman et al. [16] a shake test was also made periodically (about every third month) to check the calibration and if needed the pedometer or accelerometer was replaced by another one.

\section{STATISTICAL ANALYSES}

Statistical analyses were carried out using SPSS version 17.0 and SAS 9.2 and the statistical significance level was set at $\mathrm{p}<0.05$ (two-sided test). All continuous variables were described as mean, standard deviation (SD) and/or median, minimum and maximum and all categorical variables were described with number of and/or percentage.

The difference between steps detected by the pedometer and accelerometer and actual counted steps taken was calculated as followed: steps detected - actual counted steps and presented as error score. To avoid that positive and negative values cancelling each other out when calculating the mean error score, the value was used without + or - and presented as the absolute error score. Wilcoxon signed rank test was used to analyze systematic differences between the device at different places and actual counted steps.

Modified Bland-Altman Plots were used to graphically show the variability in error score of the pedometer and the accelerometer on the different locations [17]. Using these plots, one for each device, the distribution of error score could be illustrated along with the $95 \%$ prediction interval (95\% CI for individual observations).

Correlations between the absolute error scores and BMI, waist- and hip circumference were investigated using
Spearman correlation coefficient $\left(r_{s}\right)$. While all women performed two tests, the mean of the absolute error score in both tests was used in the calculations. Correlation was in this study defined as: little, if any $(r<0.25)$, low $(r=0.26-$ $0.49)$, moderate $(r=0.50-0.69)$, high $(r=0.70-0.89)$, and very high $(r=0.9-1.00)$ [18].

Consistency between actual steps counted and steps detected by the pedometers and the accelerometer respectively, were analyzed using intra-class correlation coefficients [19].

\section{RESULTS}

Registered numbers of steps from the pedometer and the accelerometer at different locations and the actual steps taken in all the 80 measurements (40 participants $\times 2$ measurements) are shown in Table 2 . The results indicate that steps registered with the pedometer are significantly different from actual steps counted. During some tests no steps were registered at all by the pedometers and accelerometers; Pedometer, right hip: 5 times, Pedometer, back in line with spine: 1 time, Accelerometer, around the neck: 0 times, Accelerometer, left hip: 1 time.

Error scores for the first and the second 6MWT are shown in Table 3. The mean error scores reveal that the pedometer and accelerometer underestimated steps taken.

The distribution of error scores for the pedometers and accelerometers is given in categories in Table 4. The mean distance walked was $519 \mathrm{~m}$, with an error score of $<1 \%$ corresponding to \pm 5 steps. The pedometer, right hip undercounted $80 \%$ of the time and the pedometer, back in line with the spine undercounted $61 \%$ of the time while the accelerometer, around the neck undercounted $32 \%$ and the accelerometer, left hip $55 \%$ of the time. 
Table 4. The Proportion of Tests (\%) with Pedometer and Accelerometer, which were Undercounted, Exact or Over Counted at the Different Locations

\begin{tabular}{|c|c|c|c|c|c|c|c|c|c|}
\hline & $\begin{array}{c}>50 \\
\text { Steps } \\
\text { Under } \\
\text { Count }\end{array}$ & $\begin{array}{c}\text { 21-50 } \\
\text { Steps } \\
\text { Under } \\
\text { Count }\end{array}$ & $\begin{array}{c}\text { 11-20 } \\
\text { Steps } \\
\text { Under } \\
\text { Count }\end{array}$ & $\begin{array}{c}\text { 5-10 } \\
\text { Steps } \\
\text { Under } \\
\text { Count }\end{array}$ & $<5->5$ & $\begin{array}{c}\text { 5-10 } \\
\text { Steps } \\
\text { Over } \\
\text { Count }\end{array}$ & $\begin{array}{c}\text { 11-20 } \\
\text { Steps } \\
\text { Over } \\
\text { Count }\end{array}$ & $\begin{array}{c}21-50 \\
\text { Steps } \\
\text { Over } \\
\text { Count }\end{array}$ & $\begin{array}{c}>50 \\
\text { Steps } \\
\text { Over } \\
\text { Count }\end{array}$ \\
\hline Pedometer, right hip (\%) & 45 & 16 & 9 & 10 & 19 & 1 & 0 & 0 & 0 \\
\hline Pedometer, back in line with spine (\%) & 24 & 10 & 13 & 14 & 30 & 8 & 0 & 1 & 1 \\
\hline Accelerometer, around the neck $(\%)$ & 1 & 5 & 11 & 15 & 46 & 18 & 3 & 1 & 0 \\
\hline Accelerometer, left hip (\%) & 20 & 9 & 15 & 11 & 14 & 10 & 8 & 8 & 6 \\
\hline
\end{tabular}

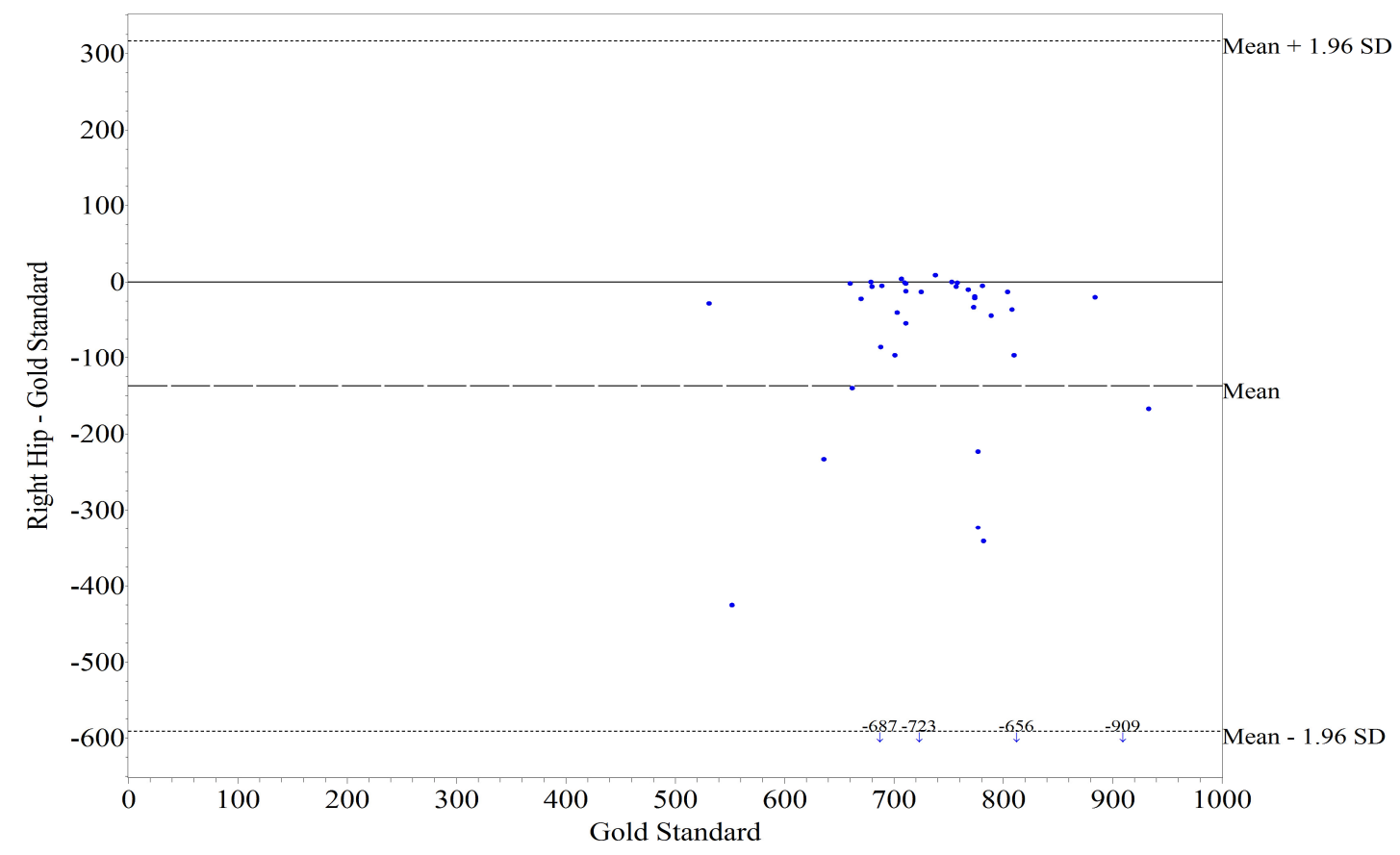

Fig. (3a). Modified Bland-Altman plot describing error score for the Silva Pedometer, location "Right Hip".

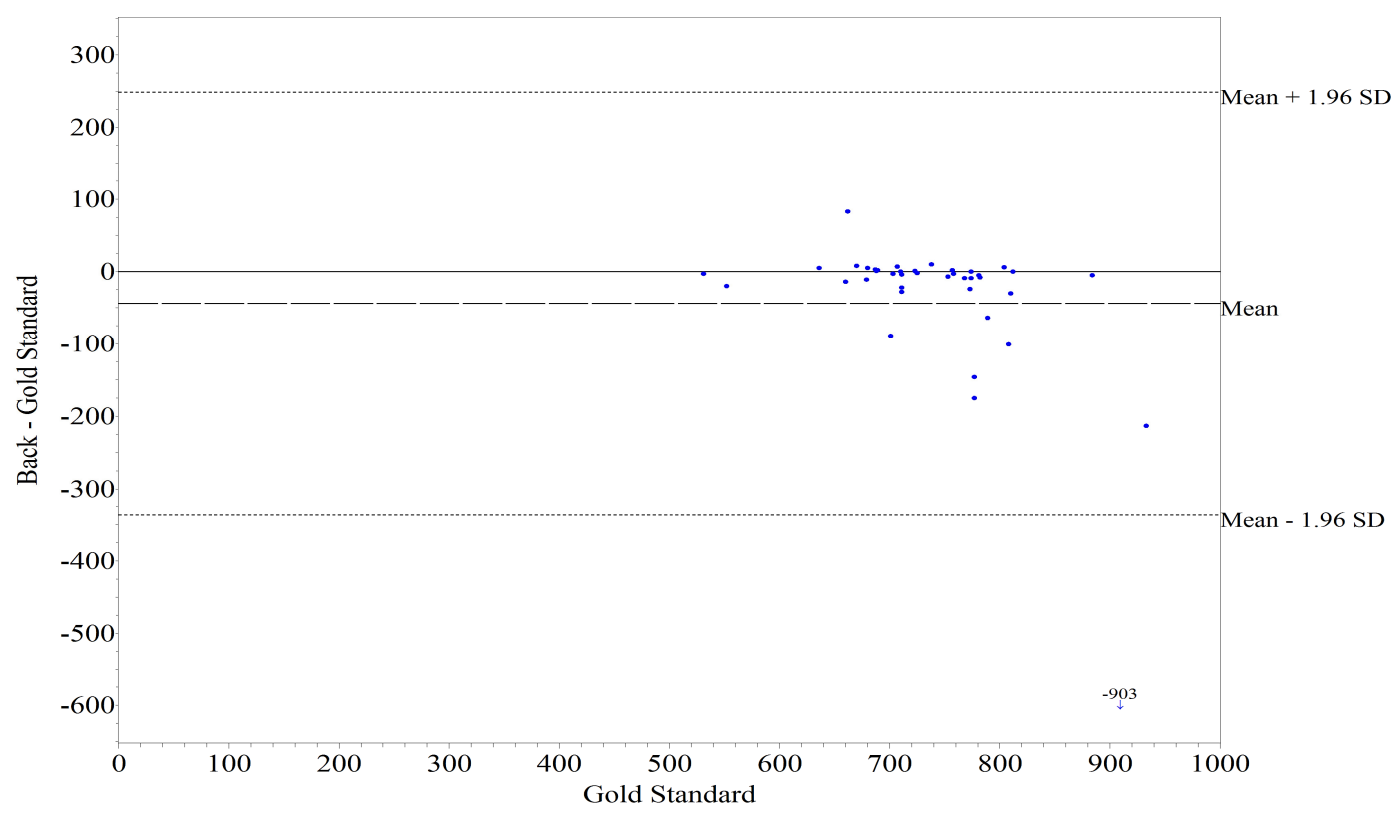

Fig. (3b). Modified Bland-Altman plot describing error score for the Silva Pedometer, location "Back in line with spine". 


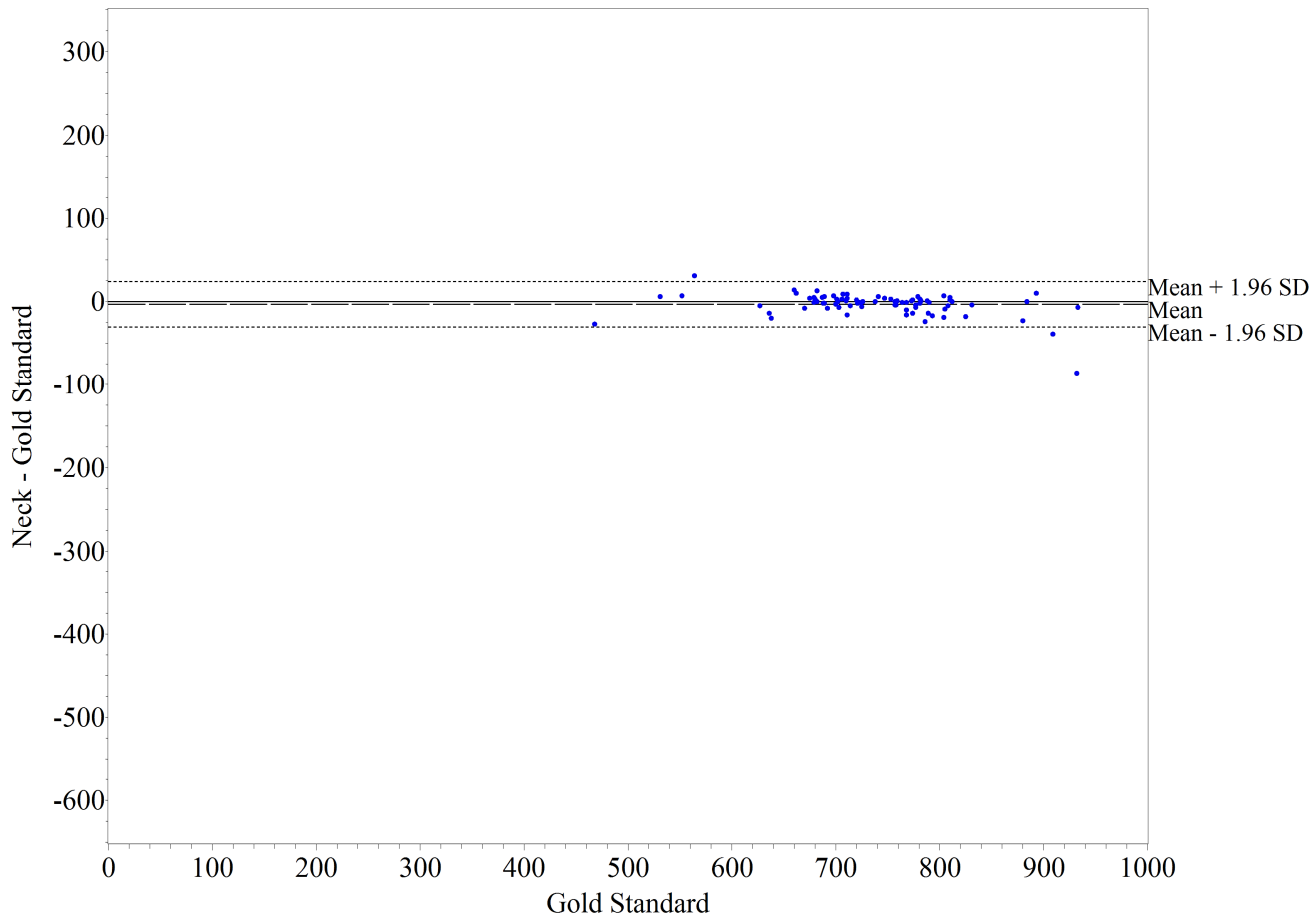

Fig. (3c). Modified Bland-Altman plot describing error score for the Silva Accelerometer, location "Around the neck".

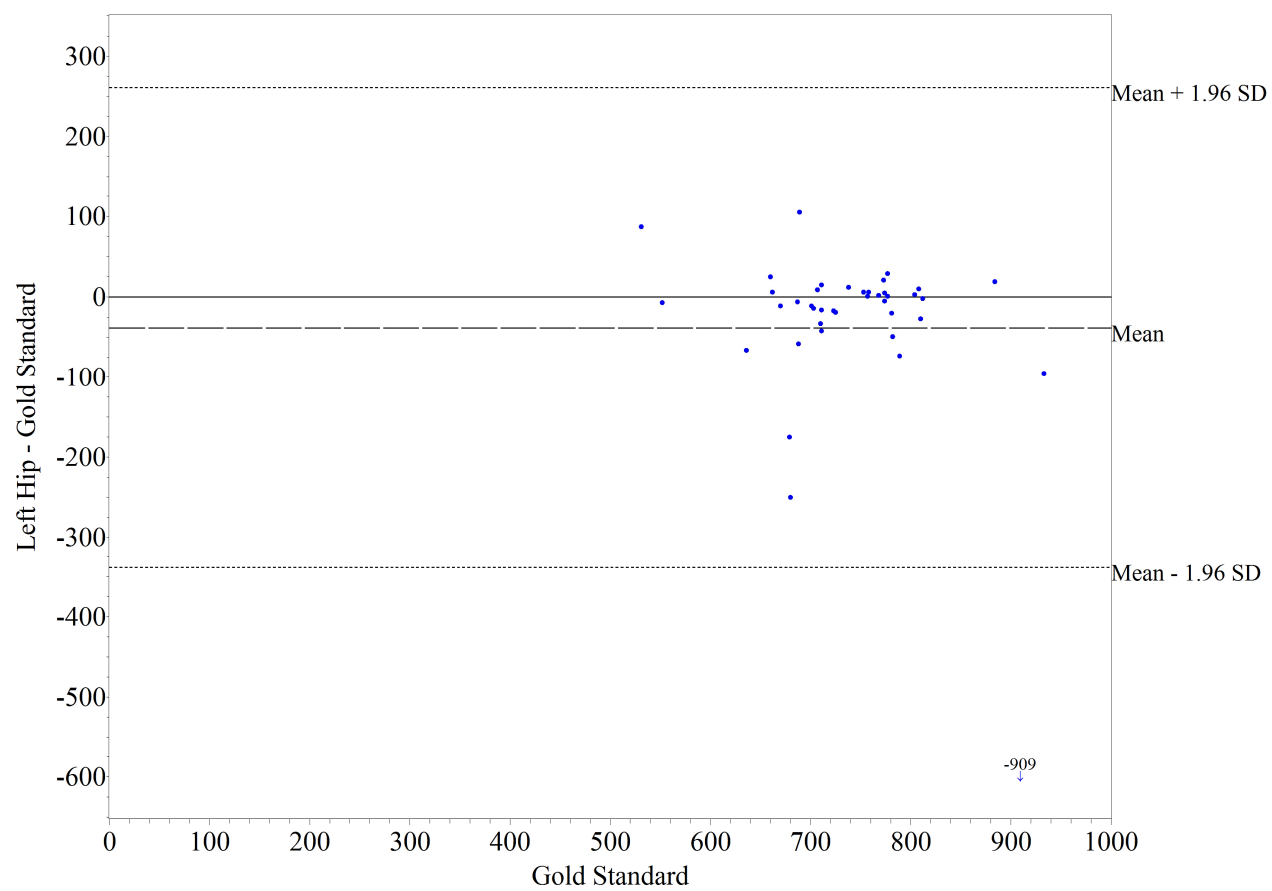

Fig. (3d). Modified Bland-Altman plot describing error score for the Silva Accelerometer, location "Left Hip".

Figs. (3a-d) show modified Bland-Altman plots for each pedometer and accelerometer at the different locations.

Wilcoxon signed rank test showed a systematic difference between pedometer, right hip $(\mathrm{p}<0.001)$, pedometer, back in line with the spine $(\mathrm{p}<0.001)$ and accelerometer, left hip $(\mathrm{p}=0.015)$ and actual steps counted. However, it demonstrated no systematic differences between accelerometer around the neck and actual steps counted $(\mathrm{p}=0.103)$.
The Spearman correlation coefficients $\left(r_{s}\right)$ between the pedometer and the accelerometer (mean of the absolute error scores) and BMI, waist circumference, hip circumference and waist to hip ratio are given in Table 5. Mean of the absolute error scores of the pedometer placed back in line with spine correlated with both BMI $\left(r_{s}=0.41, p<0.05\right)$ and hip circumference $\left(r_{s}=0.38, p<0.05\right)$. Waist circumference was correlated with mean of the absolute error scores of the accelerometer, left hip $\left(r_{s}=-0.36, p<0.05\right)$. 
Table 5. Spearman Correlation Coefficient $\left(r_{s}\right)$, Between the Pedometer and Accelerometer Plus Mean Absolute Error Scores Per Patient at the Different Locations and BMI, Waist Circumference, Hip Circumference and Waist-To-Hip Ratio During 6 MWT (n=40)

\begin{tabular}{|c|c|c|c|c|c|c|c|c|}
\hline & \multicolumn{2}{|c|}{ BMI } & \multicolumn{2}{|c|}{$\begin{array}{c}\text { Waist } \\
\text { Circumference }\end{array}$} & \multicolumn{2}{|c|}{$\begin{array}{c}\text { Hip } \\
\text { Circumference }\end{array}$} & \multicolumn{2}{|c|}{ Waist-to-hip ratio } \\
\hline & $\mathbf{r}_{\mathrm{s}}$ & p-Value & $\mathbf{r}_{\mathrm{s}}$ & p-Value & $\mathbf{r}_{\mathrm{s}}$ & p-Value & $\mathbf{r}_{\mathrm{s}}$ & p-Value \\
\hline Pedometer, right hip & 0.20 & 0.22 & 0.18 & 0.26 & 0.15 & 0.36 & 0.01 & 0.95 \\
\hline Pedometer, back in line with spine & 0.41 & 0.008 & 0.03 & 0.88 & 0.38 & 0.020 & -0.26 & 0.13 \\
\hline Accelerometer, around the neck & 0.26 & 0.11 & 0.15 & 0.36 & 0.01 & 0.95 & 0.01 & 0.96 \\
\hline Accelerometer, left hip & -0.16 & 0.31 & -0.36 & 0.022 & 0.10 & 0.54 & -0.32 & 0.052 \\
\hline
\end{tabular}

BMI; body mass index $\left(\mathrm{kg} / \mathrm{m}^{2}\right)$

The intraclass correlation coefficient (ICC) between actual steps counted and the steps registered by the Silva pedometers was 0.13 for the one placed at the right hip and 0.20 for the one placed back in line with the spine. While the ICC for the accelerometer hung around the neck was 0.99 and for the left hip 0.41 .

\section{DISCUSSION}

The main purpose of this study was to, during 6 MWT, examine the accuracy of a specific pedometer ((Silva model Pedometer Plus 56013-3, Silva Sweden AB, Sollentuna, Sweden) and accelerometer (Silva model Ex3 plus 56026, Silva Sweden AB, Sollentuna, Sweden) in women suffering from obesity. The second aim was to study if BMI, waist and hip circumference and waist-to-hip ratio had any impact on the pedometer/accelerometer location. The main finding in this study is that the accelerometer is more accurate than the pedometer. These findings are in accordance with Crouter et al. [6] who concluded that the accelerometer they tested (New Lifestyles NL-2000) was superior for use in health promotion strategies targeting overweight and obese adults than their tested pedometer (Yamax Digiwalker SW-200).

Our findings indicate that the accelerometer was more accurate when hung around the neck compared to the left hip location. This knowledge is important when using accelerometers in research to increase reliability. Why the accuracy differs between different locations needs further research.

According to our results the pedometer did not give accurate results for obese women when placed at the recommended positions at the hip or back in line with the spine. A possible explanation is that the pedometer tilted during the test, even though it was correctly positioned at the beginning. The accuracy when placed back in line with the spine was slightly better than the right hip but this placement might cause discomfort while seated. These findings are similar to those in a previous study assessing the accuracy of a similar Silva pedometer (Silva model 56012) in healthy volunteers. The authors concluded that the pedometers located over the right and left hip, were too inaccurate for activity promotion purposes, particularly in overweight and obese adults. The pedometer they used undercounted on average $67 \%$ of the time, compared to the pedometers in this study that undercounted $80 \%$ (right hip) and $61 \%$ (back in line with the spine) of the time [20]. We agree with their conclusion that undercounting is a major issue for patients aiming at taking for example 10000 steps per day. They may have to take hundreds or even thousands more steps in order to reach their goal. It is important for healthcare staff to have knowledge of this when recommending pedometer based walking exercise to women suffering from obesity.

One limitation of this study was that gold standard was registered manually. There is always a risk that manual registration can be disturbed. To address this, two tests were undertaken whereby two assistants counted steps, the results of which showed $100 \%$ agreement. This does not however confirm that all manual tests were this precise, but nonetheless indicates high reliability.

All correlations between the different locations of the tested pedometer and accelerometer and BMI, waist circumference, hip circumference and hip-to waist ratio were little (if any) to low. Crouter et al. [6] observed that the accuracy of another pedometer, using a similar springlevered mechanism, was not affected by BMI or waist circumference. However, they showed that pedometer tilt influenced the pedometer's accuracy. Another limitation of our study was that we did not check if, and to what extent, the pedometers tilted during the tests. Even if the pedometer and accelerometer were placed with no tilt at the start of the test, a tilt might have occurred during the test. A specific belt on which the pedometer and accelerometer were mounted might have been a solution; on the other hand in real life conditions the equipment is often placed on the waistband of the trousers.

A further limitation of the current study is that we cannot draw any conclusions about how accurate the pedometer and the accelerometer are during normal and slow gait as the patients walk at their maximum speed during a 6 MWT. This limits the ability to generalize. Other studies have shown that pedometer error significantly increased at slow speeds [10, $11,21,22]$. Despite these limitations the present study highlights that the location of the pedometer or accelerometer is of importance. Further studies are required to investigate the accuracy of the pedometer and accelerometer in women with overweight or normal weight.

\section{CONCLUSION}

In conclusion, the accelerometer is more accurate at registering steps taken than the pedometer in women with obesity. The location, which gave the most accurate results, 
was found to be around the neck. The accelerometer is therefore better suited for use in studies and for health promotion strategies for obese women.

\section{ACKNOWLEDGEMENTS}

This study was supported by grants from the Research and Development Council of Göteborg and Bohuslän. Silva AB, Sollentuna, Sweden supported the study with the pedometers and accelerometers used in this study.

\section{CONFLICT OF INTEREST}

The authors confirm that this article content has no conflicts of interest.

\section{REFERENCES}

[1] Swinburn BA, Caterson I, Seidell JC, James WP. Diet, nutrition and the prevention of excess weight gain and obesity. Public Health Nutr 2004; 7: 123-46.

[2] Richardson CR, Newton TL, Abraham JJ, Sen A, Jimbo M, Swartz AM. A meta-analysis of pedometer-based walking interventions and weight loss. Ann Fam Med 2008; 6: 69-77.

[3] Rooney B, Hooks T, Baciak K, Havens S, Gilles H. Minutes in motion: motivating a community to move. WMJ 2008; 107: 11823.

[4] Rooney B, Smalley K, Larson J, Havens S. Is knowing enough? Increasing physical activity by wearing a pedometer. WMJ 2003; 102: 31-6.

[5] Melanson EL, Knoll JR, Bell ML, et al. Commercially available pedometers: Considerations for accurate step counting. Prev Med 2004; 39: 361-8.

[6] Crouter SE, Schneider PL, Bassett DR Jr. Spring-levered versus piezo-electric pedometer accuracy in overweight and obese adults. Med Sci Sports Exerc 2005; 37: 1673-9.

[7] Swartz AM, Bassett DR Jr, Moore JB, Thompson DL, Strath SJ. Effects of body mass index on the accuracy of an electronic pedometer. Int J Sports Med 2003; 24: 588-92.

[8] Shepherd EF, Toloza E, McClung CD, Schmalzried TP. Step activity monitor: increased accuracy in quantifying ambulatory activity. J Orthop Res 1999; 17: 703-8.
Horvath S, Taylor DG, Marsh JP, Kriellaars DJ. The effect of pedometer position and normal gait asymmetry on step count accuracy. Appl Physiol Nutr Metab 2007; 32: 409-15.

[10] Tudor-Locke C, Williams JE, Reis JP, Pluto D. Utility of pedometers for assessing physical activity: convergent validity. Sports Med 2002; 32: 795-808.

[11] Bassett DR Jr, Ainsworth BE, Leggett SR, et al. Accuracy of five electronic pedometers for measuring distance walked. Med Sci Sports Exerc 1996; 28: 1071-7.

[12] de Souza SA, Faintuch J, Fabris SM, et al. Six-minute walk test: functional capacity of severely obese before and after bariatric surgery. Surg Obes Relat Dis 2009; 5: 540-3.

[13] Physical status: the use and interpretation of anthropometry. Report of a WHO Expert Committee. World Health Organ Tech Rep Ser 1995; 854: 1-452.

[14] Ats statement. Guidelines for the six-minute walk test. Am J Respir Crit Care Med 2002; 166: 111-7.

[15] Vincent SD, Sidman CL. Determining measurement error in digital pedometers. Meas Phys Educ Exerc Sci 2003; 7: 19-24.

[16] Sidman CL, Vincent SD, Corbin CB, Pangrazi RP, Vincent WJ. Digital pedometers: checking calibration prior to use in research. Med Sci Sports Exerc 2001; 33: 299.

[17] Bland JM, Altman DG. Statistical methods for assessing agreement between two methods of clinical measurement. Lancet 1986; 1: 307-1.

[18] Domholdt E. Rehabilitation research. Principles and applications, $3^{\text {rd }}$ ed. St Louis, MO:Elsevier Saunders 2005.

[19] Shrout PE, Fleiss JL. Intraclass correlations. Uses in assessing rater reliability. Psychol Bull 1979; 86: 420-8.

[20] Clemes SA, O'Connell S, Rogan LM, Griffiths PL. Evaluation of a commercially available pedometer used to promote physical activity as part of a national programme. Br J Sports Med 2010; 44 : 1178-83.

[21] Crouter SE, Schneider PL, Karabulut M, Bassett DR, Jr. Validity of 10 electronic pedometers for measuring steps, distance, and energy cost. Med Sci Sports Exerc 2003; 35: 1455-60.

[22] Le Masurier GC, Lee SM, Tudor-Locke C. Motion sensor accuracy under controlled and free-living conditions. Med Sci Sports Exerc 2004; 36: 905-10.

(C) Wiklund et al.; Licensee Bentham Open.

This is an open access article licensed under the terms of the Creative Commons Attribution Non-Commercial License (http://creativecommons.org/licenses/by$\mathrm{nc} / 3.0 /$ ) which permits unrestricted, non-commercial use, distribution and reproduction in any medium, provided the work is properly cited. 